\title{
Expression of the E-cadherin-catenin complex in patients with pancreatic ductal adenocarcinoma
}

\author{
Anna Pryczynicz ${ }^{1}$, Katarzyna Guzińska-Ustymowicz ${ }^{1}$, Andrzej Kemona ${ }^{1}$ \\ and Jolanta Czyżewska²
}

\author{
Departments of ${ }^{1}$ General Pathomorphology and ${ }^{2}$ Clinical Laboratory Diagnostics, \\ Medical University of Białystok, Białystok, Poland
}

\begin{abstract}
Cadherins and catenins, mediators of intercellular interactions, play a major role in adhesion. Changes in their expression and functioning reflect invasive and metastatic properties of cancer cells. The study objective was to assess changes in the expressions of E-cadherin and $\alpha-, \beta$ - and $\gamma$-catenin proteins in pancreatic duct carcinoma in correlation with clinicopathological parameters, lymph node involvement and distant metastases. Twenty-nine patients with pancreatic duct carcinoma were analyzed in relation to gender and age, histological type, histological malignancy grade $(\mathrm{G})$, local lymph node involvement and distant metastases. The expression levels of E-cadherin and $\alpha-\beta$ - and $\gamma$-catenins were subjected to immunohistochemical labeling. Reduced expression or abnormal localization of E-cadherin and $\alpha$-, $\beta$ - and $\gamma$-catenins were observed in pancreatic duct carcinoma. The statistical analysis did not show any correlations of the expressions of these proteins with gender and age of patients, histological type $(\mathrm{Hp})$, histological grade $(\mathrm{G})$ and the presence of local lymph node involvement or distant metastases. However, correlations were found between the expression of E-cadherin and $\beta$ catenin $(\mathrm{p}<0.001)$ as well of $\alpha$-catenin with $\beta$-catenin $(\mathrm{p}=0.006)$ and $\gamma$-catenin $(\mathrm{p}=0.026)$. Disorders in the expression of E-cadherin reveal strong associations with abnormal expressions of $\alpha$-, $\beta$ - and $\gamma$-catenins. Also enhanced tumor aggressiveness shows certain tendency correlations (although statistically insignificant) with the loss of E-cadherin expression and change in its localization.
\end{abstract}

Key words: E-cadherin, $\alpha$-catenin, $\beta$-catenin, $\gamma$-catenin, pancreatic ductal adenocarcinoma

\section{Introduction}

Pancreatic cancers are characterized by poor prognosis and high mortality rate. Currently, in many countries, pancreatic duct carcinoma is the fourth most common cause of death among malignant cancer patients (according to the National Cancer Register Centre in the year 1999 in Poland there were approximately 3,500 deaths due to pancreatic duct carcinoma) [1]. These data indicate great importance of the analysis of the mechanisms of invasion and metastasis of pancreatic cancers. The disease prognosis is determined by the ability of cancer cells to metastasize to local lymph nodes and distant organs [2]. Metastasis is first of all the result of the loss of intercellular interactions, i.e.

Correspondence: K. Guzińska-Ustymowicz, Dept. of General Pathomorphology, Medical University of Białystok,

Waszyngtona 13, 15-269 Bialystok, Poland; tel.: (+4885) 7485942, fax.: (+4885) 7485996,

e-mail: kasia.guzinska@gmail.com cell adhesion. Disorders affect epithelial integrity, the mechanism of cell-cell junctions becomes disturbed and cancer cells may easily infiltrate adjacent tissues, and migrate to lymphatic and blood vessels. In normal epithelium, the adhesion molecules serving as membrane receptors are responsible for intercellular interactions. E-cadherin (also known as type 1 cadherin, gene $\mathrm{CDH} 1, \mathrm{CD} 324$ ), a glycoprotein that belongs to a family of calcium-dependent receptors, is capable of mediating homotypic intercellular interactions. E-cadherin consists of the extracellular domain by which it binds to E-cadherin on an adjacent cell, the transmembrane domain and the cytoplasmic domain reacting with catenins [3]. Four types of catenins have been identified: alpha, beta, delta and gamma. $\beta$-catenin, a component of the cadherin-catenin complex, possesses an armadillo repeat domain and is thus involved in protein-protein bonds. It also functions as a component of the Wnt signaling pathway and can be an oncogene [4]. $\gamma$-Catenin (plakoglobin) has been identified as a 
Table 1. Correlation between the expression of E-cadherin and $\beta$-catenin proteins and clinicopathological parameters in pancreatic cancer.

\begin{tabular}{|c|c|c|c|c|c|c|c|}
\hline \multirow{2}{*}{\multicolumn{2}{|c|}{ Parameters }} & \multicolumn{3}{|c|}{ F-cadherin } & \multicolumn{3}{|c|}{$\beta$-catenin } \\
\hline & & \multirow{2}{*}{$\frac{\text { normal }}{6(42.9 \%)}$} & \multirow{2}{*}{$\begin{array}{l}\text { abnormal } \\
8(57.1 \%)\end{array}$} & $\mathrm{p}$ & normal & abnormal & $\mathrm{p}$ \\
\hline \multirow{2}{*}{$\mathrm{Age}$} & $<60$ & & & \multirow{2}{*}{ *NS } & $7(50 \%)$ & $7(50 \%)$ & \multirow{2}{*}{ NS } \\
\hline & $\geq 60$ & $3(20 \%)$ & $12(80 \%)$ & & $5(33.3 \%)$ & $10(66.7 \%)$ & \\
\hline \multirow{2}{*}{ Gender } & male & $7(30.4 \%)$ & $16(69.6 \%)$ & \multirow{2}{*}{ NS } & $10(43,5 \%)$ & $13(56.5 \%)$ & \multirow{2}{*}{ NS } \\
\hline & female & $2(33.3 \%)$ & $4(66.7 \%)$ & & $2(33.3 \%)$ & $4(66.7 \%)$ & \\
\hline \multirow{2}{*}{$\begin{array}{l}\text { Histological type of } \\
\text { cancer }\end{array}$} & $\operatorname{adc}$ & $9(34.6 \%)$ & $17(65.4 \%)$ & \multirow{2}{*}{ NS } & $10(38.5 \%)$ & $16(61.5 \%)$ & \multirow{2}{*}{ NS } \\
\hline & adc. muc. & $0(0 \%)$ & $3(100 \%)$ & & $2(66.7 \%)$ & $1(33.3 \%)$ & \\
\hline \multirow{2}{*}{$\begin{array}{l}\text { Grade of histological } \\
\text { malignancy }\end{array}$} & G2 & $9(36 \%)$ & $16(64 \%)$ & \multirow{2}{*}{ NS } & $10(40 \%)$ & $15(60 \%)$ & \multirow{2}{*}{ NS } \\
\hline & G3 & $0(0 \%)$ & $4(100 \%)$ & & $2(50 \%)$ & $2(50 \%)$ & \\
\hline \multirow{2}{*}{ Lymph node metastasis } & absent & $7(36.8 \%)$ & $12(63.2 \%)$ & \multirow{2}{*}{ NS } & $8(42.1 \%)$ & $11(57.9 \%)$ & \multirow{2}{*}{ NS } \\
\hline & present & $2(20 \%)$ & $8(80 \%)$ & & $4(40 \%)$ & $6(60 \%)$ & \\
\hline \multirow{2}{*}{ Distant metastasis } & absent & $7(33.3 \%)$ & $14(66.7 \%)$ & \multirow{2}{*}{ NS } & $8(38.1 \%)$ & $13(61.9 \%)$ & \multirow{2}{*}{ NS } \\
\hline & present & $2(25 \%)$ & $6(75 \%)$ & & $4(50 \%)$ & $4(50 \%)$ & \\
\hline \multirow{2}{*}{ E-cadherin } & normal & \multirow{2}{*}{\multicolumn{3}{|c|}{$\begin{array}{l}- \\
-\end{array}$}} & $8(88.9 \%)$ & $1(11.1 \%)$ & \multirow{2}{*}{$<0.0001$} \\
\hline & abnormal & & & & $4(20 \%)$ & $16(80 \%)$ & \\
\hline \multirow{2}{*}{$\beta$-catenin } & normal & $8(66.7 \%)$ & $4(33.3 \%)$ & \multirow{2}{*}{$<0.0001$} & \multirow{2}{*}{\multicolumn{3}{|c|}{$\begin{array}{l}- \\
-\end{array}$}} \\
\hline & abnormal & $1(5.9 \%)$ & $16(94.1 \%)$ & & & & \\
\hline \multirow{2}{*}{$\alpha$-catenin } & positive & $5(55.5 \%)$ & $4(44.5 \%)$ & \multirow{2}{*}{$\begin{array}{c}\text { NS } \\
(0.058)\end{array}$} & $7(77.8 \%)$ & $2(22.2 \%)$ & \multirow{2}{*}{0.006} \\
\hline & negative & $4(20 \%)$ & $16(80 \%)$ & & $5(25 \%)$ & $15(75 \%)$ & \\
\hline \multirow{2}{*}{$\gamma$-catenin } & positive & $7(41.2 \%)$ & $10(58.8 \%)$ & \multirow{2}{*}{ NS } & $9(52.9 \%)$ & $8(47.1 \%)$ & TS \\
\hline & negative & $2(16.7 \%)$ & $10(83.3 \%)$ & & $3(27.2 \%)$ & $9(81.8 \%)$ & ND \\
\hline
\end{tabular}

*NS- no statistical significance. Relationship is significant at the level of $\mathrm{p}<0.05$. Significant relationship is marked in bold.

component of desmosomes and may also bind to classical cadherins [5]. E-cadherin demonstrates specific binding to $\beta$-catenin or $\gamma$-catenin, whereas $\alpha$-catenin binds to $\beta$-catenin or $\gamma$-catenin, but not to E-cadherin. Thus, there are two types of complexes: $1 /$ the E-cadherin, $\alpha$ - and $\beta$-catenin complex and $2 /$ the E-cadherin, $\alpha$ - and $\gamma$-catenin complex [6,7]. $\alpha$-Catenin binds the cadherin-catenin complexes to actin filaments of the cytoskeleton via binding to vinculin and alpha-actin proteins. It has been also observed that $\alpha$-catenin when not in the complex with other catenins regulates arrangement of actin filaments. In this way, the cadherin/catenin complexes stabilize epithelial architecture [7,8].

There is a growing body of evidence indicating that adhesion disorders have a major role in generating invasiveness of cancer cells. Gene CDH1 mutations correlate with cancers of the stomach, colon, thyroid, breast and ovaries. Increased proliferation of these cancers and invasion of cancer cells into adjacent tissues and distant organs are associated with E-cadherin dysfunction $[6,9,10,11]$. Therefore, the aim of the current study was immunohistochemical assessment of the expressions of E-cadherin and $\alpha$-, $\beta$ - and $\gamma$-catenins in pancreatic duct carcinoma as correlated with clinicopathological parameters, lymph node involvement and distant metastases.

\section{Materials and methods}

Materials. The study was performed using archive material. The study group included 29 patients treated surgically for pancreatic duct carcinomas at the Department of General Surgery and Gastroenterology, Medical University of Białystok. The control group were 15 patients with normal pancreas. Sections, $5 \mu \mathrm{m}$-thick, were cut from paraffin blocks and stained with hematoxylin and eosin $(\mathrm{H}+\mathrm{E})$. The routine histopathological assessment of the sections referred to the histological type (adenocarcinoma and adenocarcinoma mucinosum), malignancy grade $(\mathrm{G})$, clinicopathological pTN status, regional lymph node involvement and the presence of distant metastases.

Immunohistochemistry. Immunohistochemical examination was performed according to the following protocol. Formalin-fixed, paraffin-embedded tissue specimens were cut on a microtome into $5 \mu \mathrm{m}$ sections, which were then deparaffinized in xylene and hydrated in alcohol. To expose the antigen, the slides were heated in a microwave oven for $15 \mathrm{~min}$ in citric acid buffer $(\mathrm{pH}=6.0)$. The activity of endogenous peroxidase was blocked by incubating the sections in $0.5 \%$ hydrogen peroxide in methanol. Next, the samples were incubated with monoclonal antibodies: E- cadherin (NCL-E$\mathrm{Cad}$, Novocastra Laboratories Ltd; dilution 1:50) - for $60 \mathrm{~min}, \beta$ catenin (NCL-B-CAT, Novocastra Laboratories Ltd) - for $60 \mathrm{~min}$; dilution 1:100, $\alpha$-cathenin ( $\alpha$-E-caten, Santa Cruz Biotechnology) - overnight at $4^{\circ} \mathrm{C}$, dilution 1:300 and $\gamma$-catenin $(\gamma$-catenin, Santa Cruz Biotechnology) - overnight at $4^{\circ} \mathrm{C}$, dilution 1:100. Reaction was performed in $\mathrm{ABC}$ technique using Novostain Super $\mathrm{ABC}$ Universal Kit (NCL-ABCm, Novocastra Laboratories Ltd.). Color 
Table 2. Correlation between the expression of $\alpha$-catenin, $\gamma$-catenin proteins and clinicopathological parameters in pancreatic cancer.

\begin{tabular}{|c|c|c|c|c|c|c|c|}
\hline \multirow{2}{*}{\multicolumn{2}{|c|}{ Parameters }} & \multicolumn{3}{|c|}{$\alpha$-catenin } & \multicolumn{3}{|c|}{$\gamma$-catenin } \\
\hline & & \multirow{2}{*}{$\frac{\text { positive }}{6(42.9 \%)}$} & \multirow{2}{*}{$\begin{array}{c}\text { negative } \\
8(57.1 \%)\end{array}$} & $\mathrm{p}$ & positive & negative & $\mathrm{p}$ \\
\hline \multirow{2}{*}{$\Lambda \mathrm{ge}$} & $<60$ & & & \multirow{2}{*}{ "NS } & $9(64.3 \%)$ & $5(35.7 \%)$ & \multirow{2}{*}{ NS } \\
\hline & $\geq 60$ & $3(20 \%)$ & $12(80 \%)$ & & $8(53.3 \%)$ & $7(46.7 \%)$ & \\
\hline \multirow{2}{*}{ Gender } & male & $8(34.8 \%)$ & $15(65.2 \%)$ & \multirow{2}{*}{ NS } & $13(56.5 \%)$ & $10(43.5 \%)$ & \multirow{2}{*}{ NS } \\
\hline & female & $1(16.7 \%)$ & $5(83.3 \%)$ & & $4(66.7 \%)$ & $2(33.3 \%)$ & \\
\hline \multirow{2}{*}{$\begin{array}{l}\text { Ilistological type of } \\
\text { cancer }\end{array}$} & adc & $8(30.8 \%)$ & $18(69.2 \%)$ & \multirow{2}{*}{ NS } & $15(57.7 \%)$ & $11(42.3 \%)$ & \multirow{2}{*}{ NS } \\
\hline & adc.muc. & $1(33,3 \%)$ & $2(66.7 \%)$ & & $2(66.7 \%)$ & $1(33.3 \%)$ & \\
\hline \multirow{2}{*}{$\begin{array}{l}\text { Grade of histological } \\
\text { malignancy }\end{array}$} & $\mathrm{Gi2}$ & $8(32 \%)$ & $17(68 \%)$ & \multirow{2}{*}{ NS } & $15(60 \%)$ & $10(40 \%)$ & \multirow{2}{*}{ NS } \\
\hline & G3 & l $(25 \%)$ & $3(75 \%)$ & & $2(50 \%)$ & $2(50 \%)$ & \\
\hline \multirow{2}{*}{ Lymph node melastasis } & absent & $5(26.3 \%)$ & $14(73.7 \%)$ & \multirow{2}{*}{ NS } & $10(52.6 \%)$ & $9(47.4 \%)$ & \multirow{2}{*}{ NS } \\
\hline & present & $4(40 \%)$ & $6(60 \%)$ & & $7(70 \%)$ & $3(30 \%)$ & \\
\hline \multirow{2}{*}{ Distant metastasis } & absent & $5(23.8 \%)$ & $16(76.2 \%)$ & \multirow{2}{*}{ NS } & $11(52.4 \%)$ & $10(47.6 \%)$ & \multirow{2}{*}{ NS } \\
\hline & present & $4(50 \%)$ & $4(50 \%)$ & & $6(75 \%)$ & $2(25 \%)$ & \\
\hline \multirow{2}{*}{ F-cadherin } & normal & $5(55.5 \%)$ & $4(44.5 \%)$ & \multirow{2}{*}{$\begin{array}{c}\text { NS } \\
(0.058)\end{array}$} & $7(77.8 \%)$ & $2(22.2 \%)$ & \multirow{2}{*}{ NS } \\
\hline & abnormal & $4(20 \%)$ & $16(80 \%)$ & & $10(50 \%)$ & $10(50 \%)$ & \\
\hline \multirow{2}{*}{$\beta$-catenin } & normal & $7(58.3 \%)$ & $5(41.7 \%)$ & \multirow{2}{*}{0.006} & $9(81.8 \%)$ & $3(27.2 \%)$ & \multirow{2}{*}{ NS } \\
\hline & abnormal & $2(11.8 \%)$ & $15(88.2 \%)$ & & $8(47.1 \%)$ & $9(52.9 \%)$ & \\
\hline \multirow{2}{*}{$\alpha$-catenin } & positive & \multirow{2}{*}{\multicolumn{3}{|c|}{ - }} & $8(88.9 \%)$ & $1(11.1 \%)$ & \multirow{2}{*}{0.026} \\
\hline & negative & & & & $9(45 \%)$ & $11(55 \%)$ & \\
\hline \multirow{2}{*}{$\gamma$-catenin } & positive & $8(47.1 \%)$ & $9(52.9 \%)$ & \multirow{2}{*}{0.026} & & - & \\
\hline & negative & $1(8.3 \%)$ & $11(91.7 \%)$ & & & - & \\
\hline
\end{tabular}

NS- no statistical significance. Relationship is significant at the level of $\mathrm{p}<0.05$. Significant relationship is marked in bold.

reaction for peroxidase was done with $\mathrm{DAB}$ chromogen (DAKO S3000, DAKO, Poland).

A semiquantitative method was used to evaluate E-cadherin and $\beta$-catenin expressions, which were defined as follows: 0 score: no expression; 1 score: expression in cytoplasm, 2 score: decreased expression, 3 score: expression at cell membrane. A score of 0 to 2 was defined as abnormal expression for E-cadherin and $\beta$-catenin. The $\alpha$ - and $\beta$-catenin expressions were observed in the cytoplasm and were defined as positive (reaction present in $\geq 50 \%$ of tumor cells) or negative (lack of reaction or reaction present in $<50 \%$ of tumor cells)

Statistical analysis. Spearman's correlation coefficient was used for statistical analysis. A p-value of $<0.05$ was considered statistically significant.

\section{Results}

\section{Expressions of $E$-cadherin and $\alpha$-, $\beta$ - and $\gamma$ - catenin proteins in normal pancreas}

In normal pancreas, membrane expressions of E-cadherin and $\beta$-catenin were observed in the glandular cells of the pancreas, in pancreatic duct epithelial cells and in the islets of Langerhans. However, $\alpha$-catenin and $\gamma$-catenin proteins were localized in the cytoplasm of these cells. Stromal expression of these glycoprotein and proteins was negative.

\section{Expressions of E-cadherin and $\alpha$-, $\beta$ - and $\gamma$ - catenins in pancreatic cancer cells}

In pancreatic duct carcinoma, loss in membrane E-cadherin expression was noted in $30 \%$ of cases $(9 / 29)$, in cytoplasmic expression in $20.7 \%$ (6/29) of cases, whereas in $48.3 \%(14 / 29)$ of cases no expression was found. Similar results were obtained for $\beta$-catenin expression, which in pancreatic duct cancer cells was present in cell membrane in $20.7 \%(6 / 29)$ of cases, in the cytoplasm in $27.6 \%(8 / 29)$ of cases, lack of expression being noted in $51.7 \%(15 / 29)$ of cases. Nuclear expression of $\beta$-catenin was negative. The expression levels of $\alpha$ - and $\gamma$-catenin proteins in the cytoplasm of cancer cells were lower as compared to normal pancreatic cells in 30\% (9/29) and $58.6 \%(17 / 29)$ of cases, respectively.

The statistical analysis of the results revealed no correlations of the protein expressions with gender and age of patients, histological type (Hp), histological grade $(G)$ and the presence of local lymph node involvement or distant metastases (Tables 1, 2). However, correlations were found between the expression of E-cadherin and $\beta$-catenin $(p<0.0001)$ as well of $\alpha$ catenin with $\beta$-catenin $(p=0.006)$ and $\gamma$-catenin $(\mathrm{p}=0.026)$. 

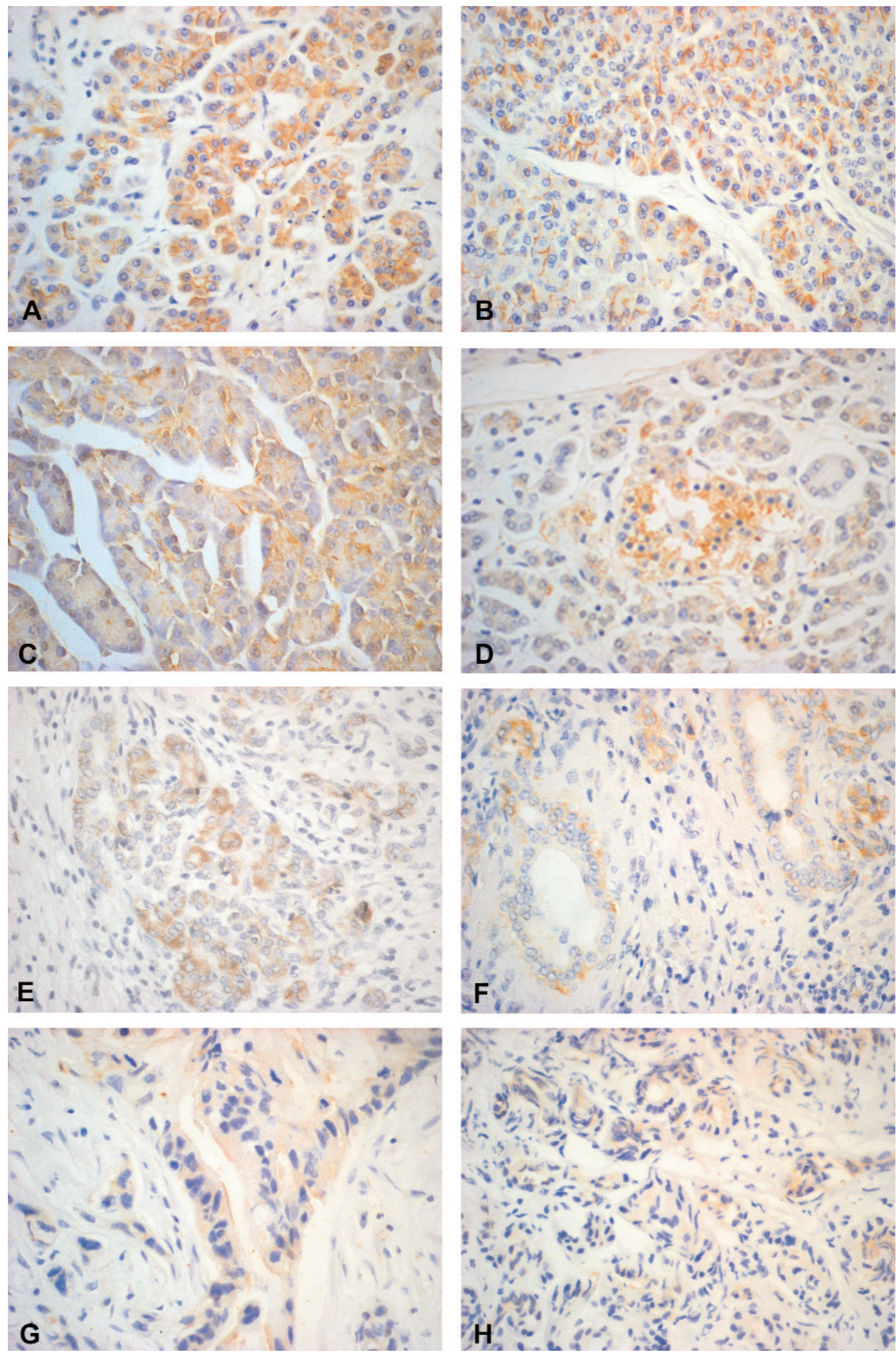

Fig. 1. Immunohistochemical staining.Normal pancreatic tissue shows membrane reaction for E-cadherin (A) and $\beta$-catenin (B), and cytoplasmic reaction for $\alpha$-catenin $\gamma(\mathbf{C})$ and $\gamma$-catenin (D). Pancreatic duct carcinoma tissue shows cytoplasmic or absent reaction for E-cadherin $(\mathbf{E})$ and $\beta$-catenin $(\mathbf{F})$ and lower cytoplasmic reaction for for $\alpha$-catenin $\gamma(\mathbf{G})$ and $\gamma$-catenin $(\mathbf{H})$. 


\section{Discussion}

Adhesion molecules are responsible for cell-cell and cell-intercellular environment interactions, creating appropriate tissue architecture. E-cadherin and catenins form functional complexes that maintain cell adhesion. The role of adhesion proteins in neoformation involves angiogenesis, loss of tissue continuity, lack of cell-cell contact and contact with extracellular matrix, which promotes neoplastic spread via metastasis formation. Loss of cancer cell adhesion precedes the process of metastases. Cancer cells lose intercellular adhesion potential and are able to migrate outside the primary tumor area to the lymphatic vessels, metastasizing to lymph nodes or to the blood vessels to form distant metastases. These processes have been confirmed by other researchers who showed decreased or negative expressions of E-cadherin and $\alpha-, \beta$ - and $\gamma$ catenins or abnormal localization of these proteins in cancer cells [12-15]. In our study, immunohistochemical staining revealed that E-cadherin protein lost its functionality, showing cytoplasmic expression or a complete lack of expression. This may be due to Ecadherin defects, such as lack of the cytoplasmic domain leading to loss of interaction with catenins, lack of the extracellular domain (E-cadherin is not able to form bonds with cadherin on an adjacent cell), gene mutations and deletions, chromatin reorganization, hypermethylation or loss of transcription factors [16]. Moreover, some oncogene products destabilize the effects of the cadherin-catenin complexes. Physiologically, free catenins are phosphorylated by glycogen synthase kinase-3 $\beta$ (GSK-3 $\beta$ ) and quickly degraded. When the Wnt pathway becomes activated, GSK-3 $\beta$ protein is blocked and catenins are accumulated in high concentration in the cytoplasm. Then, they are transferred to the cell nucleus where they bind to the transcription factors TCF/LEF-1, thus affecting the expression of target genes. Some authors have observed nuclear expression of $\beta$-catenin in pancreatic cancer, which could indicate that carcinogenesis is also associated with the Wnt pathway $[17,18]$. We observed a distinct loss of membranous and cytoplasmic $\beta$ catenin expression and no nuclear reaction with GSK$3 \beta$, which could suggest that the Wnt pathway had not been activated and free catenins had been degraded with GSK-3 involvement. On the other hand, Zeng et al. [19] observed activation of the Wnt/ $\beta$-catenin pathway in $65 \%$ of pancreatic cancer cases, irrespective of mutation in $\beta$-catenin gene. They also noted an increase in the content of GSK-3 $3 \beta$ protein in pancreatic cancer cells and accumulation of E-cadherin protein in the cytoplasm, which however did not impair the Ecadherin $/ \beta$-catenin complex.

However, it has been proved that abnormal expressions of E-cadherin and $\alpha$-, $\beta$ - and $\gamma$-catenins are associated with clinicopathological parameters. According to Joo et al. [12], reduced expressions of E-cadherin and $\alpha$ - and $\beta$-catenin are related to histological malignancy grade. The expression levels of these proteins are lower in low-differentiated carcinomas. Also in our study, E-cadherin showed abnormal expression in adenocarcinoma mucinosum and G3 tumors in as many as $100 \%$ of cases, although no statistical significance was noted. Karayiannakis et al. [14] have found that the expression of $\alpha$ - and $\beta$-catenin correlates with the presence of local lymph node involvement and distant metastases, whereas abnormal expression of $\beta$-catenin correlates only with lymph node involvement. Although with no statistically significant correlations, we observed disorders in E-cadherin and $\beta$-catenin expressions in as many as $75 \%$ of cases with distant metastases. Moreover, other researchers have found that the expressions of E-cadherin and $\alpha$-catenin correlate with survival of patients suffering from pancreatic duct carcinomas. Julkunen et al. [15] have also demonstrated that the expression of all catenins $(\alpha, \beta$, $\gamma)$ is associated with worse prognosis. Besides, $\mathrm{Li}$ et al. [20] have concluded that changes in the expression of E-cadherin and $\alpha$-catenin (reduced expression and abnormal distribution in the cell) are connected with an early phase of pancreatic duct carcinoma, whereas a complete loss of these proteins is associated with advanced pancreatic cancer. Our findings showed no correlation of the expressions of E-cadherin and $\alpha-, \beta-$ and $\gamma$-catenin with any of the clinicopathological parameters suggesting tumor growth.

Despite the lack of correlation between the clinicopathological parameters and the expressions of E-cadherin and $\alpha-, \beta$ - and $\gamma$-catenins, the expressions of Ecadherin and $\beta$-catenin showed abnormal localization in cancer cells. Moreover, a correlation was found between disturbances in localization of E-cadherin and $\beta$-catenin, which is consistent with observations reported by other authors. Our findings indicate strong correlations of E-cadherin expression disorders with $\alpha-, \beta$ - and $\gamma$-catenins and certain tendency associations, although statistically insignificant, of the increase in tumor aggressiveness with the loss of Ecadherin expression and change in its localization. However, such a small group of cases does not allow definite conclusions. The study should be continued on an enlarged group of patients.

\section{References}

[ 1] Landis SH, Murray T, Bolden S, et al. Cancer statistics, 1999. CA Cancer J Clin. 1999;49:8-31.

[2] Warshaw AL, Fernandez-Del Castillo C. Pancreatic carcinoma. N Engl J Med. 1992;326:455-465.

[3] Kemler R. From cadherins to catenins: cytoplasmic protein interactions and regulation of cell adhesion. Trends Genet. 1993;9:317-321.

[ 4] Weis WI, Nelson WJ Re-solving the Cadherin-Catenin-Actin Conundrum. J Biol Chem. 2006;281:35593-35597. 
[ 5] Cowin P, Kapprell HP, Franke WW, et al. Plakoglobin: a protein common to different kinds of intercellular adhering junctions. Cell. 1986;46:1063-1073.

[ 6] Beavon I: The E-cadherin-catenin complex in tumor metastasis: structure, function and regulation. Eur $J$ Cancer. 2000;36:1607-1620.

[ 7] Drees F, Pokutta S, Yamada S, et al. Alpha-catenin is a molecular switch that binds E-cadherin-beta-catenin and regulates actin-filament assembly. Cell. 2005;123:903-915.

[8] Knudsen KA, Soler AP, Johnson KR, et al. Interaction of alpha-actinin with the cadherin/catenin cell-cell adhesion complex via alpha-catenin. J Cell Biol. 1995;130:67-77.

[9] Birchmeier W, Behrens. Cadherin expression in carcinomas: role in the formation of cell junctions and the prevention of invasiveness. Biochim Biophys Acta. 1994;1198: 11-26.

[10] Bracke ME, van Roy FM, Mareel MM. The Ecadherin/catenin complex in invasion and metastasis. Curr Top Microbiol Immunol. 1996;213:123-161.

[11] Nowak M. et al. Expression of E-cadherin, beta-catenin and Ki-67 antigen and their reciprocal. Folia Histochem Cytobiol. 2007;45:233-238.

[12] Joo YE, Rew JS, Park CS, et al. Expression of E-cadherin, $\alpha$ and $\beta$-catenins in patients with pancreatic adenocarcinoma. Pancreatology. 2002;2:129-137.

[13] Yonemasu H, Takashima M, Nishiyama KI, et al. Phenotypical characteristic of undifferentiated carcinoma of the pancreas: a comparison with pancreatic ductal adenocarcinoma and revelance of E-cadherin $\alpha$ catenin and $\beta$ catenin expression. Oncol Rep. 2001;8:745-752.
[14] Karayiannakis AJ, Syrigos KN, Polychronidis A, et al. Expression patterns of alpha-, beta- and gamma-catenin in pancreatic cancer: correlation with E-cadherin expression, pathological features and prognosis. Anticancer Res. 2001;21:4127-4134.

[15] Julkunen K, Makinen K, Karja V, et al. alpha-, beta- and chicatenin expression in human pancreatic cancer. Anticancer Res. 2003;23:5043-5047.

[16] Yoshiura K, Kanai Y, Ochiai A, et al. Silencing of the E-cadherin invasion-suppressor gene by $\mathrm{CpG}$ methylation in human carcinomas. Proc Natl Acad Sci USA. 1995;92:7416-7419.

[17] Al-Aynati M, Radulovich N, Riddell R, et al. Epithelial-cadherin and $\beta$-catenin expression changes in pancreatic intraepithelial neoplasia. Clinical Cancer Research. 2004;10:12351240.

[18] Lowy AM, Fenoglio-Preiser C, Kim OJ, et al: Dysregulation of $\beta$-catenin expression correlates with tumor differentiation in pancreatic duct adenocarcinoma. Ann Sur Oncol. 2003;10:284-290.

[19] Zeng G, Germinaro M, Micsenyi A, et al. Abberant Wnt/3catenin signaling in pancreatic adenocarcinoma. Neoplasia. 2006;8:279-289.

[20] Li YJ, Meng YX, Ji XR: Relationship between expressions of E-cadherin and alpha-catenin and biological behaviors of human pancreatic cancer. Hepatobiliary Pancreat Dis Int. 2003;2:471-477.

Submitted: 30 June, 2009 Accepted after reviews: 13 October, 2009 